\title{
Clínica Psicológica Ampliada em IST/HIV-Aids: Sentidos Produzidos por Psicólogas no SUS
}

\author{
Emilly Sales Sala Gomes ${ }^{1}$ \\ ${ }^{1}$ Universidade Federal da Bahia, BA, Brasil.
}

\author{
Mônica Lima ${ }^{1}$ \\ ${ }^{1}$ Universidade Federal da Bahia, BA, Brasil.
}

\begin{abstract}
Resumo: Este estudo buscou compreender as práticas discursivas de psicólogas(os) sobre a atuação psicológica na abordagem às IST/HIV-Aids em serviços especializados em uma cidade da Bahia. Para tanto, foram realizadas nove entrevistas semiestruturadas com profissionais ligadas(os) a serviços da rede pública de saúde. A perspectiva teórico-metodológica da psicologia social construcionista inspirou o processo de produção e análise das informações. Os resultados apontaram para importantes rupturas e ressignificações dos repertórios linguísticos gestados no cotidiano das práticas em saúde (tempo vivido e tempo curto), em atenção às necessidades dos contextos de atuação, ainda que elementos da formação clássica da psicologia também sejam utilizados para caracterizar a atuação nesses espaços. Nos serviços pesquisados, as(os) psicólogas(os) têm conseguido enxergar e reconhecer demandas de ordens biológica e social, que indicam aspectos objetivos da vivência dos(as) usuários(as) (menos afeitos ao ideário individualista), apontando para uma contextualização da clínica psicológica no campo da saúde pública, embora nem todas(os) admitam que essas demandas devam ser cuidadas também pela(o) profissional de psicologia. Do ponto de vista teórico, partimos de reflexões sobre as noções de clínica ampliada e de atuação psicológica coletiva até alcançarmos a noção de clínica psicológica ampliada, situada em relação às especificidades da atuação psicológica no campo do HIV-Aids. Nessa direção, a clínica psicológica ampliada apresenta-se em potencial construção, situando-se entre aproximações e recuos do que seria uma prática desenvolvida de modo contextualizado e comprometido com os processos subjetivos de pessoas vivendo com HIV-Aids ou tentando se proteger em situações concretas de vulnerabilidade, que geram sofrimento psicossocial.
\end{abstract}

Palavras-chave: Atuação psicológica, IST/HIV-Aids, Clínica ampliada, Psicologia social, Práticas discursivas.

\section{Amplified Clinic in STI/HIV-AIDS: Meanings Produced by Psychologists in Brazilian Health Public System (SUS)}

\begin{abstract}
This study aimed to understand the discursive practice of psychologists regarding the psychological practice in the approach to STI/HIV-AIDS in specialized services in a city of Bahia. To do so, we conducted nine semi-structured interviews with professionals related to health public services. The theoretical-methodological perspective of social constructionist psychology inspired the process of information production and analysis. The results pointed towards important ruptures and resignifications of the linguistic repertoires created in the everyday health practices (lived time and short time), attentive to the needs of the contexts of practice, although elements of traditional psychology training are also used to characterize the work in these contexts. In the surveyed services, the psychologists have been noticing and recognizing biological and social demands, which indicate objective aspects of the users' experience (less adept to individualistic values). This fact points towards a contextualization in the psychological work in the public health field, although not all interviewed psychologists admit that this type of demand should also be addressed by psychology professionals.
\end{abstract}


From a theoretical point of view, we started from reflections on the notions of amplified clinic and the collective psychological practice resulting in the concept of amplified psychological clinic that relates to specificities of the psychological work in the field of HIV-AIDS. In this respect, the amplified psychological clinic is in potential construction, approaching and retreating from what would be a developed practice contextualized and committed to the subjective processes of people living with HIV-AIDS or trying to protect themselves in concrete vulnerable situations, which produces psychosocial suffering.

Keywords: Psychological practice, STI/HIV-AIDS, Amplified clinic, Social psychology, Discursive practice.

\title{
Clínica Psicológica Ampliada en ITS/VIH-sida: Sentidos Producidos por Psicólogas en el Sistema Único de Salud (SUS)
}

\begin{abstract}
Resumen: Este estudio pretende comprender las prácticas discursivas de psicólogas/os sobre la acción psicológica para abordar las infecciones de transmisión sexual y el sida (ITS/VIH-sida) en servicios asistenciales especializados en una ciudad de Bahía (Brasil). Con este fin, se realizaron nueve entrevistas semiestructuradas con profesionales vinculados a los servicios de salud pública. La perspectiva teórico-metodológica de la psicología social construccionista inspiró el proceso de producción y análisis de datos. Los resultados apuntaron a importantes rupturas y resignificaciones de los repertorios lingüísticos producidos en la práctica diaria de la salud (tiempo vivido y tiempo corto), atentos a las necesidades de los contextos de acción, aunque también se utilizan elementos de la formación clásica de la psicología para caracterizar la práctica en esos espacios. En los servicios investigados, las/los psicólogas/os han podido ver y reconocer las demandas y sus dimensiones biológicas y sociales, que indican aspectos objetivos de la experiencia de los/as usuarios/as (poco afectados por los ideales individualistas), apuntando a una contextualización de la clínica psicológica en el contexto de la salud pública, aunque no todos admiten que estas demandas también deban ser atendidas por el profesional de la psicología. Del punto de vista teórico, partimos de reflexiones sobre las nociones de clínica ampliada y acción psicológica colectiva hacia llegar a la noción de clínica psicológica ampliada, situada en la relación con las especificidades de la acción psicológica en el campo del VIH/sida. En ese sentido, la clínica psicológica ampliada es una potencial construcción, que tiene lugar entre aproximaciones y retrocesos de lo que sería una práctica desarrollada de manera contextualizada y comprometida con los procesos subjetivos de las personas que viven con $\mathrm{VIH} /$ sida o que intentan protegerse en situaciones concretas de vulnerabilidad, que generan sufrimiento psicosocial.
\end{abstract}

Palabras clave: Acción psicológica, ITS/VIH-sida, Clínica ampliada, Psicología social, Prácticas discursivas.

\section{Introdução}

O movimento de mudanças no Sistema Nacional de Saúde, desde os anos 1980, foi fator determinante da inserção e nuanças da atuação das(os) psicólogas(os) no campo da saúde pública (Yamamoto \& liveira, 2010). A partir dos movimentos das Reformas Sanitária e Psiquiátrica, as políticas de saúde passaram a priorizar o trabalho das equipes multiprofissionais como meio de aprimorar a qualidade dos atendimentos e de valorizar os(as) trabalhadores(as) da saúde. Essa nova perspectiva do cuidado em equipe favoreceu a entrada de muitos(as) profissionais nesse campo e a psicologia foi uma das categorias profissionais mais favorecidas por essa inserção (Dimenstein \& Macedo, 2012).

Porém, com a complexidade de atuação no campo da saúde pública, fundamentada em uma 
compreensão ampliada de saúde, com ênfase nos conceitos de promoção da saúde e prevenção das doenças, considerando os contextos de vida e adoecimento dos indivíduos, a psicologia tem sofrido críticas desde essa inserção, devido ao fato de suas ferramentas permanecerem as mesmas (Dimenstein, 2000; Dimenstein \& Macedo, 2012; Pires \& Braga, 2009). Essa atuação exige transformações de teorias e práticas, não circunscritas ao campo da saúde mental, mas que colaborem para o processo de saúde, considerando seus contextos e necessidades integrais.

Também na década de 1980, foi identificada mundialmente uma doença denominada de Síndrome da Imunodeficiência Adquirida (Sida), conhecida no Brasil como Aids. As transformações político-sociais que marcaram essa década influenciaram e direcionaram decisões e ações políticas também no campo das infecções sexualmente transmissíveis (IST/HIV-Aids). Nesse contexto, as políticas públicas no âmbito da Aids incluíram a atuação de psicólogas(os) nas equipes multiprofissionais desde sua implantação, inserindo-as(os) na elaboração de políticas e programas, na efetivação de ações programáticas previstas e no monitoramento das ações (Conselho Federal de Psicologia [CFP], 2008).

Segundo Perucchi, Rodrigues, Jardim e Calais (2011), as(os) psicólogas(os) que atuam com pessoas vivendo com HIV-Aids e suas famílias têm a possibilidade de desenvolver um trabalho relevante de reconhecimento de vulnerabilidades, promoção de direitos humanos e garantia de uma atenção à subjetividade das pessoas que vivem (PVHIV) e convivem com o HIV-Aids, em um contexto de dificuldades de garantia de direitos e exercício da cidadania. Nessa perspectiva, é necessário que a atuação da(o) psicóloga(o) envolva também sua inserção no sistema de saúde brasileiro, na compreensão de seus programas e análises epidemiológicas, bem como o conhecimento acerca de assuntos relacionados ao HIV, como a conjuntura em que a epidemia se insere, o trabalho e militância de organizações não governamentais, as repercussões biológicas da infecção e os variados aspectos sociais que a caracterizam. Nesse cenário, o princípio da integralidade da atenção à saúde, preconizado pelo Sistema Único de Saúde (SUS), convida as(os) psicólogas(os) a construírem práticas e intervenções que considerem as diversas dimensões do processo saúde-doença-cuidado, em articulação com os(as) demais profissionais e serviços para garantia da resolutividade da atenção.
Diversos estudos que discutem a inserção da psicologia em serviços públicos de saúde e, mais recentemente, na assistência social, têm se apropriado do conceito de clínica ampliada para designar práticas psicológicas mais engajadas com as necessidades dos contextos de atuação (Dettmann, Aragão, \& Margotto, 2016; Ferreira Neto, 2008; Schneider, Oltramari, Budde, Silveira, \& Silveira, 2016; Sundfeld, 2010). Originário do campo da Saúde Coletiva, o termo clínica ampliada foi proposto por Campos (1996/1997), em uma tentativa de problematização da clínica (biomédica) nos serviços públicos de assistência à saúde.

Almejando a superação do modelo biomédico, centrado na doença e no corpo, a noção de clínica ampliada propõe a "transformação da atenção individual e coletiva, de forma que possibilite que outros aspectos do Sujeito, que não apenas o biológico, possam ser compreendidos e trabalhados pelos profissionais de saúde" (Cunha, 2005, p. 12). Assim, a clínica ampliada reivindica a saída da zona de conforto em vários âmbitos do trabalho em saúde, exigindo a ampliação do objeto da clínica (dimensão social e subjetiva, e não somente biológica) ou daquilo sobre o qual se trabalha; do objetivo da clínica (curativo, preventivo, de reabilitação e também o grau de autonomia das pessoas) ou da finalidade do trabalho em saúde; e, por consequência, dos meios de intervenção (sejam eles diagnósticos ou terapêuticos) utilizados para atender às necessidades do campo (Campos \&Amaral, 2007).

No contexto da atuação psicológica, a construção da clínica ampliada tem sido compreendida com base em atuações que questionem práticas individualizantes e descontextualizadas, a fim de viabilizar a invenção de novos fazeres e saberes nos diversos espaços de atuação. Ferreira Neto (2008) salienta, porém, que o surgimento das "práticas emergentes" não necessariamente garantiu o engajamento sociopolítico dessas práticas. Assim, ocorrem desde simples adaptações até atuações inovadoras. Para Sundfeld (2010), é necessário tomar cuidado quando da utilização da expressão clínica ampliada como qualificadora das práticas, para que ela não mascare velhos modos de atuar. Dessa maneira, estudos que busquem compreender como e em que medida novas práticas psicológicas têm sido gestadas nos serviços públicos de assistência à saúde são relevantes e profícuos.

O objetivo do presente artigo é caracterizar as práticas discursivas de psicólogas(os) sobre os saberes e fazeres da clínica psicológica em serviços especializados 
em IST/HIV-Aids em uma cidade da Bahia. Partimos da noção de clínica não como uma área, mas como uma forma de abordar, uma forma de olhar, uma ética que orienta a atuação (Costa \& Brandão, 2005).

\section{Método}

A investigação científica é aqui entendida como uma prática reflexiva e crítica (Spink\& Menegon, 2013) por meio da qual buscamos explicitar os processos pelos quais as pessoas constroem sentidos e versões da realidade. Coerentes com esse referencial, adotamos a perspectiva teórico-metodológica das práticas discursivas e produção de sentidos (Spink, 2010). Assim, analisamos a atuação profissional considerando o tempo longo de construções de conteúdos culturais, que conformam os discursos de uma determinada época, mas que continuam como possibilidades de sentido em outras conjunturas históricas. Entendendo, porém, a dinamicidade das produções de sentido, foi fundamental levar em conta também o tempo curto das interações, quando as produções cumulativas são ressignificadas no tempo de vida (tempo vivido) de cada um de nós, nos processos de socialização (Spink, 2010; Spink \& Matta, 2007).

Foram realizadas entrevistas semiestruturadas com nove psicólogas(os), sete de sexo feminino e dois do sexo masculino, com idades entre 29 e 58 anos e tempos de formação e atuação diferenciados, vinculadas(os) a quatro serviços de referência em IST/HIV-Aids oferecidos pelo SUS em uma cidade da Bahia, trabalhadoras(es) das Secretarias Estadual e Municipal de Saúde.

Os discursos foram analisados à luz da análise categorial temática, seguindo as etapas de pré-análise, codificação e categorização, com o fim de entender padrões discursivos compartilhados, compreender as funções de cada enunciado e o contexto que possibilitou sua emergência (Vázquez-Sixto, 1996). A primeira etapa, pré-análise, caracterizou-se pelo processo de organização do material para análise - com a realização de leituras sucessivas -, pelo estabelecimento dos objetivos da análise e pela definição do corpus documental. A etapa codificadora correspondeu à fragmentação do texto, em unidades de registro e unidades de contexto, e à catalogação de seus elementos. Essa etapa objetivou transformar os dados brutos em dados úteis. Por fim, a etapa de categorização permitiu a construção de uma visão condensada do material, por meio do agrupamento dos fragmentos por critérios de analogia (Vázquez-Sixto, 1996).
Dessa maneira, apresentamos a temática "Sentidos da clínica psicológica nos serviços públicos de IST/ HIV-aids", um dos capítulos da dissertação intitulada "Práticas discursivas sobre atuação psicológica em HIV-aids: sentidos produzidos no cotidiano dos serviços públicos de saúde em uma cidade da Bahia" (Gomes, 2018), que se refere à caracterização da clínica psicológica ofertada nos serviços de IST/HIV-Aids e que abarca três categorias: a primeira delas, intitulada objeto da clínica, diz respeito ao objeto sobre o qual essa clínica se debruça, englobando o contexto, as pessoas e suas demandas; a segunda, denominada objetivo da clínica, refere-se às finalidades que orientam as práticas psicológicas em IST/HIV-Aids; por último, os meios de intervenção apresentam os recursos e estratégias utilizados pelas(os) profissionais para acessar o objeto e alcançar os objetivos dessa clínica.

Esta pesquisa foi submetida e aprovada pelo comitê de ética e pesquisa do Instituto de Psicologia da Universidade Federal da Bahia, com número de CAAE 74489317.9.0000.5686, e seguiu as normas das Resoluções n. 466/2012 e n. 510/2016 do Conselho Nacional de Saúde.

\section{Resultados e discussão}

\section{Objeto da clínica: o contexto, as pessoas e suas demandas}

As teorias que orientam a clínica psicológica, pautadas no individualismo moderno, tomaram a subjetividade, o psiquismo e a interioridade como objetos de sua clínica. Uma das críticas da pós-modernidade à psicologia clínica refere-se, justamente, à priorização da dimensão subjetiva em suas intervenções, em detrimento das dimensões biológica, histórica e social (Moreira, Romagnoli, \&Neves, 2007;Portela, 2008). Para Portela (2008), "a ênfase na subjetividade levou as teorias da psicologia ao seu caráter abstracionista, ou seja, tornou-as inclinadas a separar o fenômeno psicológico do sujeito que o produz, objetivando estes dois fatos e enfatizando o primeiro em detrimento do segundo" (p. 138). Em contraponto a essa perspectiva, a ampliação do objeto da clínica psicológica ocorreria se, na concretude da prática profissional, elementos do contexto social e da biologia dos sujeitos tivessem espaço de escuta e fossem transformados em foco das intervenções realizadas pelas(os) profissionais. 
No cenário de atenção às IST/HIV-Aids, as(os) psicólogas(os) referem que as demandas percebidas no cotidiano de suas práticas e objeto de suas intervenções, assumem peculiaridades a depender da lógica de funcionamento dos serviços. Os(as) usuários(as) atendidos(as) individualmente pela psicologia são pessoas que acessaram o serviço com alguma queixa de IST ou necessidade de realização de testagem para HIV-Aids, sífilis e hepatites (em decorrência de violência sexual, acidentes com perfurocortantes etc.), ainda que as demandas não se restrinjam à vivência da sexualidade ou de uma possível infecção. O viver com HIV, no entanto, aponta para atenção da psicologia em alguns momentos particulares dessa vivência.

Eu acho que tem dois momentos que geralmente é... os usuários, usuárias demandam a escuta psicológica. O primeiro momento, né? O momento da descoberta mesmo, do vírus, é... e aí as pessoas, elas não, ainda não sabem como lidar com aquela informação, é... algumas ficam reativas, outras ficam muito assustadas, né? Todas as mudanças necessárias pra... a partir, né? Desse, dessa nova condição. É... as relações familiares, para quem contar, como contar, o medo de perder o emprego... então, tudo isso mobiliza bastante no momento da descoberta. Então a escuta psicológica ela é bastante requisitada nesse momento. E, o outro momento, é o momento das parcerias. Quando a pessoa conhece alguém, se interessa por alguém, começa um relacionamento. . . Então, acho que esses são os dois momentos cruciais (Acácia, comunicação pessoal, 22 de outubro de 2017).

O momento do diagnóstico inicial foi destacado por todas(os) as(os) profissionais entrevistadas(os) como o momento em que a psicologia mais é demandada. Um estudo realizado por Massignani, Rabuske, Backes e Crepaldi (2014), que buscou investigar as práticas de revelação diagnóstica em HIV-Aids por profissionais de saúde em serviços especializados, destaca as repercussões de atuar na comunicação de diagnósticos positivos para HIVaids, exigindo muitas vezes que o(a) profissional conte com o acompanhamento psicológico, tanto como estratégia de encaminhamento de pacientes, quanto para buscar apoio para si próprio. Somado a isso, na presente pesquisa a maior demanda de atendimento psicológico associada ao diagnóstico também pode dar-se por ser o único instante em que, na maioria dos serviços, o(a) usuário(a) é convocado(a) a passar pelo atendimento psicológico, pelo próprio fluxo protocolar do serviço.

A vivência do estigma e do preconceito também aparece e muitas vezes corresponde ao fator que mobiliza o retorno dos(as) pacientes ao atendimento psicológico, mesmo após anos de diagnóstico. Estudos que investigam PVHIV demonstram que o preconceito ainda é uma realidade no enfrentamento dessa infecção e o quanto dificulta a construção de qualidade de vida dos(as) usuários(as) (Garbin, Garbin, Moimaz, \& Carmo, 2009; Jesus et al., 2017; Meira et al., 2017). Esse aspecto aparece assim no nosso estudo:

Então... vou te dar um exemplo. . . Tinha um paciente que tinha acabado de ter o diagnóstico e tava lutando muito, muito, muito pra aceitar esse diagnóstico. E vinha realmente num acompanhamento ao longo da... enfim, da história dele, da história da sexualidade, dos relacionamentos... vinha se aproximando mais de uma aceitação. Um belo dia ele tava aí na recepção, como os serviços são interligados, então às vezes é comum que um paciente do multicentro acabe descendo ou passando por aqui. Ele tava na recepção esperando consulta, aí passou uma senhora com uma menina mais nova e aí falou assim baixinho "aqui que ficam os aidéticos". E aí ele ouviu, assim, nesse dia uma evolução que a pessoa vinha no processo de aceitação... entrou aqui na sala, praticamente tudo perdido. Porque lidou, enfrentou o preconceito (Dália, comunicação pessoal, 26 de janeiro de 2018).

No âmbito das relações afetivo-sexuais, o medo de relacionar-se, de ter que contar sobre o diagnóstico e não saber a reação do parceiro(a) ainda é uma questão para muitos usuários(as). Sobre esse aspecto, as(os) profissionais destacam alguns dramas da vivência da soropositividade para o HIV entre as mulheres, que tornam essa experiência ainda mais delicada. A violência das relações entre homens e mulheres, por exemplo, muitas vezes torna a mulher refém de uma relação sem o uso do preservativo e, quando descobre a soropositividade, tem medo de conversar com o parceiro sobre isso, com receio de sua reação. $\mathrm{Ou}$, ainda, o drama de poder passar para o filho o 
vírus do HIV, quando gestante, drama que o homem não vivencia na mesma proporção. Outros estudos já abordam a maior vulnerabilidade feminina diante da infecção pelo HIV, devido aos arranjos afetivo-sexuais dos quais participam, que envolvem fantasias de proteção, inclusive presentes entre os homens, mas também organizam-se em torno do afeto e da própria fidelidade (Galindo, Francisco, \& Rios, 2013; Melo et. al, 2017). Na presente pesquisa, as(os) psicólogas(os) têm observado que muitas dessas mulheres acabam optando pelo desinvestimento dos relacionamentos afetivo-sexuais quando descobrem o diagnóstico positivo para HIV, como destacam outros estudos (Silva, 2017; Silva \& Albuquerque, 2007). Isso sugere uma atenção psicológica orientada pelas questões de gênero e suas repercussões. Vejamos o plano discursivo de uma de nossas entrevistadas:

Aqui eu lido muito mais com a experiência masculina homossexual. Tem muita mulher? Tem. Mas esse dilema de "ai, como é que eu arranjo um namorado, como é que eu conto pro meu namorado" muitas vezes não chega aqui, por motivos diversos. Ou porque a mulher descobriu junto com o parceiro e resolveu não deixar o parceiro, né? Por motivos diversos: por amor, porque pensa que nunca vai conseguir ninguém ou algumas mulheres que descobrem que têm, não ficam mais com o parceiro anterior, terminou por alguma razão. Mas também se desinvestem totalmente da vida afetiva, pensam: "não, não quero mais saber disso. Agora eu vou só criar meu filho e trabalhar", né? E aí elas mesmo não sentem isso como uma questão e terminam não chegando aqui. Eu acabo ouvindo mais isso em conversas informais ou em outros tipos de atendimento. É mais raro a mulher chegar com essa angústia de "ai, eu preciso arranjar um namorado, eu preciso contar pro meu namorado que eu tenho HIV". Esse assunto é uma questão mais dos homens (Dália, comunicação pessoal, 26 de janeiro de 2018).

O reconhecimento de elementos de gênero em suas práticas sinaliza que as(os) profissionais têm incorporado aspectos do contexto social mais amplo no cotidiano dos seus atendimentos. Para Monteiro e Figueiredo (2009), incorporar discussões relacionadas aos papéis de gênero, vulnerabilidade social e pauperização nos atendimentos de atenção às IST/HIV-Aids é não apenas reconhecer as questões imediatas do tratamento em saúde, como também legitimar elementos externos ao setting imediato dos atendimentos. Porém, no contexto de atenção às IST nos serviços públicos de saúde, segundo a fala de algumas entrevistadas(os), a presença desses elementos configura o próprio setting terapêutico, não devendo ser vistos como externos a ele.

Algumas profissionais, quando se referem ao objeto da clínica psicológica nos serviços de atenção às IST/HIV-Aids, enfatizam a importância de enxergar as pessoas atendidas para além dos rótulos das doenças, aproximando-se da perspectiva de consideração do sujeito inteiro, como proposto pela noção de clínica ampliada em saúde (Campos \& Amaral, 2007). Como destacado na fala da profissional:

Eu, eu não gosto de dizer essas pessoas como diferentes de outras. . . Então eu não posso dizer que especificamente paciente de HIV é... me traz algo diferente, né? Ao contrário, eu acho até que a gente tá, tem que [cuidar] de sempre escutar as pessoas. Tirar esses rótulos, né? Aquele, aquele paciente com Aids, aquele paciente com câncer... eu sou contra essas especialidades da psicologia. Porque eu acho que eu não tô aqui pra escutar câncer, nem pra escutar Aids, nem tô aqui pra escutar... pessoas! Né? Nem dizer assim, "ah, cê tá escutando é, o trans..." eu... lógico que as pessoas trazem, é... sofrimentos diferentes, especificidades dentro das suas histórias... mas todas trazem, não é? . . . Então eu acho que são pessoas, são sempre pessoas [com] especificidades (Margarida, comunicação pessoal, 06 de outubro de 2017).

Apesar disso, sublinhamos que esse posicionamento no processo de escuta clínica psicológica também pode encobrir uma dificuldade de incorporar as dimensões objetivas do adoecimento por uma IST acompanhada de tantos impactos orgânicos e sociais. A ampliação da clínica psicológica pressupõe que as dimensões orgânicas, sociais e subjetivas do adoecimento pelo HIV-Aids, encarnadas em um sujeito, sejam objeto das intervenções profissionais; ou seja, essa clínica preconiza que todos esses aspectos estejam presentes nas práticas em saúde (Campos, 1996/1997). Dessa forma, enxergar as pessoas é também enxergar suas doenças, mas não apenas elas.

Em suma, as práticas discursivas descritas sinalizam uma ampliação dos sentidos produzidos no 
cotidiano do trabalho sobre o objeto da clínica psicológica nesses espaços, não circunscrito apenas à dimensão subjetiva e interiorizada dos sujeitos, mas também incluindo as vivências sociais e culturais de pessoas que vivem com uma infecção carregada de tantos estigmas e preconceitos, como é o caso do HIV-Aids. Essa ampliação parece ter incorporado mais elementos da dimensão social do que dos aspectos relacionados à dimensão biológica dos problemas de saúde das pessoas atendidas.

\section{Objetivo da clínica: finalidade da atuação psicológica em IST/HIV-Aids}

Campos e Amaral (2007) definem que a ampliação do objetivo da clínica pressupõe que o(a) profissional almeje não apenas a produção de saúde, por meio dos recursos curativos, preventivos, de reabilitação e/ou cuidados paliativos, mas também a construção da autonomia dos(as) usuários(as), entendida como a capacidade dos sujeitos em lidarem com suas próprias redes ou sistemas de dependência. No âmbito da atuação psicológica, é necessário conceber a construção da autonomia por meio de intervenções que considerem os contextos em que as pessoas estão inseridas e suas redes de relação, sem desconsiderar as ações que busquem a promoção da saúde e prevenção das doenças.

As(os) psicólogas(os) entrevistadas(os) destacaram que, nos serviços de atenção às IST/HIV-Aids, os objetivos das intervenções variam conforme a atividade proposta e as pessoas que estão sendo acompanhadas. Dessa forma, algumas ações (e algumas posturas profissionais) permitem que os elementos da produção da saúde e construção da autonomia estejam mais claramente presentes como finalidades das práticas nesses espaços.

Objetivando a construção de pessoas mais autônomas, uma das profissionais problematiza o conceito de autonomia como uma estratégia de construção da cidadania na população atendida pelos serviços de saúde pública. Dessa forma, ela sinaliza a importância de realizar intervenções que acompanhem o caminhar das pessoas dentro dos serviços de saúde, emprestando-lhes o poder contratual (Tykanori, 2001) na luta pela garantia de seus direitos, em especial do direito constitucional à saúde.

Eu falo assim, às vezes no SUS a gente meio que... em algum momento, aquilo que eu falei de ser um pouco bengala do paciente. Não é que a gente vai ficar bengalando ele a vida toda, mas em algum momento você precisa fazer uma bengalinha pra ele. ... Então, assim, eu acho que o SUS tem essa visão dessa... né? Pelo menos eu entendo isso, e que o terceirizado, e que as coisas, os serviços terceirizados não, a pessoa tem que ter autonomia. "Tá, meu amor, mas autonomia não é todo mundo que tem, autonomia é algo que a gente tem que ajudar às vezes a pessoa a construir". ... Eu já cansei de sair de lá de cima, com a mão, quase dada a mão do paciente para chegar aqui e dizer: "Olha, fulana, atenda esse paciente, a situação é essa, essa...", porque você sabe que o paciente não vai conseguir quebrar esse bloqueio, ser compreendido e você faz isso. Nisso você vai ajudando ele também a entender o que é que... como é que ele pode caminhar, quais são os direitos dele, entendeu?... Claro, tem gente que nunca vai ter e aí você vai ter que ir dando os limites, vai ter que ir, né? Mas, de forma geral, no início você primeiro dá isso daí, pra depois você ver como é que essa pessoa vai caminhar e muitas vezes, depois, você vê que ela caminha, ela vai caminhando, entendeu? (Hortência, comunicação pessoal, 07 de novembro de 2017).

Tykanori (2001, p. 55) propõe a noção de poder contratual referindo-se ao "valor previamente atribuído para cada indivíduo dentro do campo social, como pré-condição para qualquer processo de intercâmbio", de trocas. A sua discussão remete-se ao campo da saúde mental, em que à pessoa com transtorno mental é negado qualquer poder de contratualidade pela negação de seus bens, mensagens e afetos. Porém, parece-nos que essa definição também é apropriada para pensar o lugar que ocupam os(as) usuários(as) dos serviços públicos de saúde, que têm muitos dos seus direitos violados e pouco desenvolvido o sentido de cidadania, de modo que necessitam desse empréstimo de contratualidade, como expresso pela entrevistada (Tykanori, 2001).

Na direção das ações de produção de saúde, as(os) psicólogas(os) denotam que as atividades externas, aquelas realizadas em períodos de campanha ou em articulação com outras instituições, têm por finalidade prevenir infecções e doenças, promover a saúde, incentivar a testagem e a vinculação das pessoas aos serviços de referência. Os aconselhamentos individual e coletivo também 
seguem a mesma lógica da prevenção e promoção da saúde, acrescida da lógica da redução de danos para uma das profissionais entrevistadas.

Porém, a maioria das(os) entrevistadas(os) refere que, mesmo nos atendimentos de núcleo profissional (Campos, 2000), ou seja, nos atendimentos individuais realizados pela psicologia, elementos e princípios que norteiam a prática nos serviços de saúde do SUS compõem as intervenções e ações psicológicas, em que a noção de estratégias de prevenção orienta os fazeres e impõe rotinas e procedimentos:

Mesmo no atendimento é... individual em psicologia a gente acaba discutindo [estratégias de prevenção]. É... como que... como se prevenir numa relação hétero, como se prevenir numa relação entre duas mulheres, entre dois homens..., né? Então, são dinâmicas mesmo da prevenção que eu acho que não... classicamente [risos] talvez as psicólogas não façam, né? E, e aí também é... eu, eu sempre falo pras estagiárias pra gente também ter uma visão integral, né? Da, da saúde (Acácia, comunicação pessoal, 22 de outubro de 2017).

Reconhecer que as ações desenvolvidas nesses serviços exigem um posicionamento diferenciado sobre o fazer da(o) psicóloga(o), distante de uma perspectiva mais clássica da formação em psicologia, envolve enxergar-se em um papel profissional engajado com a lógica do SUS. Essa atuação não foi caracterizada como antagônica ao papel da psicologia, mas como uma continuidade da prática profissional, com adaptação dos objetivos às necessidades do contexto de atuação. Isso diverge da tradição de resultados de pesquisas dentro da psicologia da saúde, nas quais a atuação psicológica foi por muito tempo retratada como uma prática descontextualizada, demasiadamente identificada com um modelo clínico tradicional/clássico, autônomo e liberal de atuação (Dimenstein, 2001; Ferreira Neto, 2010; Lo Bianco, Bastos, Nunes, \& Silva, 1994).

As(os) profissionais, de forma geral, avaliaram que suas formações acadêmicas contribuíram pouco para a efetivação das práticas que realizam nos serviços de IST/HIV-Aids. Nesse cenário, um aspecto que destacaram foi a formação forjada na prática, no cotidiano dos fazeres no contexto da saúde. Uma psicóloga ressaltou, por exemplo, que precisou realizar uma releitura da clínica, do modelo tradicional em que foi formada, para atuar no contexto da saúde pública/coletiva e das demandas do HIV-Aids, onde ela intitula necessitar pensar em uma "clínica do social". Nesse sentido, a atuação forma e força novos olhares, de modo que a graduação aparece como o início de um processo formativo que necessita de certa abertura e autonomia posterior da(o) profissional para dar conta dos diversos desafios percebidos em suas práticas.

A nossa formação também ela, ela ganha um, um, vamos dizer assim, um plus, né? Ela ganha algo a mais, porque... é... a gente tem a possibilidade de conhecer diversas coisas diferentes. Pelo fato de ser um serviço especializado, você não pode perder de vista os outros espaços da rede, então você tem que ter uma... uma visão bastante ampliada sobre todos os espaços que a rede tá te oferecendo. ... Então são espaços que eu acho que são bastante enriquecedores pra prática, né? Até... só que você tem que tá aberta, pra entender que... a... todos os espaços podem se tornar um setting [risos] (Acácia, comunicação pessoal, 22 de outubro de 2017).

A postura das(os) psicólogas(os) entrevistadas(os) aponta, ainda, para a superação da dicotomia, apresentada por Lima (2005), entre o exercício da psicoterapia como "ideal de atuação" psicológica, mesmo nos serviços públicos de saúde, e as outras práticas realizadas pelas(os) profissionais, diante da impossibilidade de realização de psicoterapias, denominadas pela autora como para-psicoterapias. Apesar disso, a fala de algumas entrevistadas(os) é marcada por uma tentativa de diferenciação entre a atuação da psicologia em serviços públicos de saúde, especificamente dos que tratam das IST/HIV-Aids, e a prática "clínica clássica" deatuaçãoda(o) psicóloga(o).Issoocorre, possivelmente, pela incorporação de repertórios discursivos construídos dentro do tempo longo de construção da psicologia e renovados pelos tempos vivido e curto (Spink, 2010), que ainda performam essas práticas.

Dessa forma, as finalidades da atuação psicológica nos serviços de IST/HIV-Aids diferenciam-se segundo as características dos serviços, das atividades e da clientela atendida. Mas, de forma geral, comportam elementos de construção da autonomia dos(as) usuários(as) atendidos(as), sem, contudo, desconsiderar aspectos da produção de saúde, presentes inclusive nos atendimentos individuais da psicologia. Isso vai ao encontro do que Campos e Amaral (2007) definem 
como ampliação do objetivo da clínica nos serviços de saúde pública. É importante ressaltar, porém, que características das(os) profissionais entrevistadas(os) também influenciam o maior ou menor engajamento na ampliação da clínica psicológica, de modo que não se configura uma homogeneidade de graus de investimento na construção dessa prática.

\section{Meios de intervenção: articulando dimensões sociais e subjetivas da abordagem em HIV-Aids}

Segundo Campos e Amaral (2007), a ampliação do objeto e do objetivo da clínica, força, necessariamente, uma revisão dos meios de intervenção para que abarquem a complexidade da inclusão das dimensões sociais e subjetivas no cuidado em saúde, e não apenas a biológica. No contexto de atuação psicológica, em que a dimensão subjetiva ocupa uma centralidade, consideramos que a ampliação dos meios de intervenção ocorre na proporção em que aspectos da condição biológica das pessoas e dos contextos social, cultural, de gênero e racial em que estão inseridas encontram ressonância nos atendimentos psicológicos para serem alvo de intervenções, respeitando-se, obviamente, os limites das atribuições e competências da psicologia para intervenções no campo da saúde.

Alguns estudos que caracterizam a atuação da psicologia no contexto das políticas de HIV-Aids destacam o papel da epidemia no questionamento de práticas tradicionais, exigindo alternativas no cuidado em saúde diante da complexidade das demandas relacionadas à infecção (Perucchi et al., 2011; Rasera \& Issa, 2007). Dessa maneira, as(os) psicólogas(os) são convidadas(os) a ampliar a atuação para além dos moldes da clínica clássica, inserindo-se em atividades diversificadas para atender aos diferentes objetivos propostos pelas políticas e programas. No contexto dos serviços de saúde pesquisados, as(os) profissionais ressaltaram a multiplicidade de ações em que estão inseridas(os).

O trabalho nesse espaço ele tem que ser diversificado, mas com um péna prevenção, um péno tratamento... Um pouco do individual, também do coletivo... A nossa equipe é... é e foi uma equipe às vezes mais do que multidisciplinar, uma equipe mesmo interdisciplinar. A minha postura também é de no trabalho tentar fazer o trabalho interdisciplinar (Magnólia, comunicação pessoal, 22 de outubro de 2017).

Desse modo, as(os) psicólogas(os) envolvem-se em todas as atividades do serviço que não são específicas de nenhum núcleo profissional, que podem ser exercidas por qualquer profissional das diversas profissões de saúde, aquelas entendidas como pertencentes a um campo de saberes (por exemplo, os aconselhamentos pré e pós teste, salas de espera, atividades externas), mas também desenvolvem as atividades típicas do núcleo de fazeres e saberes (Campos, 2000) da psicologia, como o atendimento psicológico individualizado.

Nos atendimentos realizados, na relação intersubjetiva profissional-usuário(a) - aparentemente afinadas(os) com o que Lima (2005) denomina de escuta cautelosa, que busca integrar as "impurezas" dos discursos dos segmentos populacionais mais vulneráveis, em uma tentativa de aproximação e compreensão da visão de mundo daquele que elabora a fala algumas(os) profissionais consideram as dimensões biológica e social do processo saúde-doença-cuidado, reconhecendo os limites de a psicologia isoladamente promover o bem-estar das pessoas, tentando construir com o(a) usuário(a) e com a equipe de saúde outras estratégias que possam ser aliadas para a construção e manutenção da saúde. Configuram-se, dessa maneira, atuações menos centradas no psicologismo, menos focadas no que Lo Bianco et al. (1994) denominam de enfoque intraindividual.

A gente acaba discutindo muitas coisas. Questões nutricionais, né? Ainda que, que é... eu não seja nutricionista [risos], óbvio, e aí... mas a gente discute, por exemplo, se a pessoa tiver tendo algum problema com a dieta, algo assim, né? Principalmente após $a, a \ldots$ a adesão aos medicamentos. $E$ aí a gente discute isso, como é que isso tá acontecendo, né? E realmente você percebe...é,é, é... que, que houve realmente uma mudança, eu busco encaminhar pra os serviços do município onde tenha uma nutricionista que possa atender, né? Algumas questões sociais, também, aí eu acabo encaminha pra, pra o serviço social. A gente acaba discutindo, é,é... eu acho que, pela natureza do serviço, a gente acaba discutindo diversas questões, né? (Acácia, comunicação pessoal, 22 de outubro de 2017). 
Como a gente não tem um grupo, eu acabo funcionando muito... isso, assim, não faz parte da psicologia, não é coisa da faculdade, mas eu acabo funcionando muito como é... mediadora, né? Dessas experiências. O paciente começa a tomar medicação, né? E aí isso é muito do senso comum mesmo, algumas são indicações médicas outras são do senso comum, essas indicações que às vezes eu passo de um para o outro. Tá tomando a medicação, tá se sentindo muito mal pela manhã, depois que toma, e aí, por, pela experiência que eu tenho de escuta dos pacientes e não porque eu li em algum artigo ou o médico me falou, muitos me falaram jáquese sentem melhorquandofazematividade física de manhã. Toma a medicação, fazem uma atividade física e aí é como se não tivesse esse efeito colateral. Não temos um grupo pra eles compartilharem isso, então eu sigo de mediadora [risos], né? Você já experimentou alguma atividade física? Aliás isso é uma coisa que eu sugiro pra várias, vários outros motivos, né? Pra quem tem insônia, pra quem tá... para quem aquela... aquele período de ajustamento tá ultrapassando já os limites e quase chegando numa depressão, que tende a se, se acentuar no final da tarde e início da noite, eu penso com o paciente "o que é que você gosta de fazer nesse horário, você não quer dar uma caminhada, você não tem alguém que você queira visitar?" Né? (Dália, comunicação pessoal, 26 de janeiro de 2018).

Monteiro e Figueiredo (2009) argumentam que o(a) trabalhador(a) de saúde, quando esbarra com os limites de seu conhecimento técnico, procura, em seu repertório de experiências reunidas no decorrer de sua vivência prática, elementos para elaboração de meios mais acertados para responder às exigências que escapam à competência do saber especializado. Tal apropriação somente é possível no decurso de sua atuação, ao longo do tempo, como "processo de aquisição e sistematização da aprendizagem informal dentro do contexto de atuação" (p. 74). Essa compreensão, concebida na práxis profissional, corresponde a um significativo contraponto ao conhecimento acadêmico, adquirido nos cursos de graduação (Monteiro, 2006). Nesse sentido, Figueiredo (2004) propõe que a sistematização do conhecimento informal, adquirido no decorrer da atuação, é capaz de formar um background que favoreça a construção de uma maior autonomia por parte dos(as) profissionais, transformando-os em sujeitos ativos na construção do cuidado em saúde.

A clínica ampliada em saúde pressupõe o compartilhamento do cuidado como forma de garantir-se a integralidade da atenção à saúde. A construção dessa clínica, no contexto de uma pesquisa sobre a atuação da(o) psicóloga(o) em saúde mental na rede pública de assistência, concretizou-se por meio de duas dimensões das práticas psicológicas: uma dimensão coletiva, de uma clínica "feita por muitos" (Ferreira Neto, 2008, p. 115), em diversos contextos de atuação, e a tentativa de articulação da dupla condição do(a) usuário(a), como sujeito e cidadão.

Nessa direção, algumas profissionais afirmaram indicar recursos disponíveis na rede social ou virtual de pessoas vivendo com HIV-Aids (RNP, ONGs, grupos virtuais etc.) como formas de ofertar suporte às pessoas atendidas pelos serviços, em uma perspectiva de intersetorialidade do cuidado em saúde. Esses recursos são indicados especialmente se os(as) usuários(as) contam suas experiências como se fossem únicas ou quando é identificada uma rede de apoio restrita, tentando fazer com que eles(as) se identifiquem com seus pares. Dessa maneira, as(os) profissionais tentam alcançar a dimensão social do cuidado em saúde, compreendendo a característica do isolamento social (Silva, 2017; Silva \& Albuquerque, 2007) que muitas vezes caracteriza a descoberta da soropositividade.

Eu indico sempre grupos virtuais, né? . . . As pessoas que eu indico e que elas realmente procuram e se inserem nesses grupos, elas gostam, bastante. Porque você tem uma questão geográfica, então ela tá aqui em [nome da cidade], mas tá conversando com alguém de Recife, com alguém de Natal, com alguém de Porto Alegre, então, não tem a possibilidade de... esbarrar com a pessoa nem no serviço, nem na rua, nem no trabalho. É... são grupos que costumam ser secretos, então, é... e, e muitos têm nomes que não dão muito indicação do que, do que são (Acácia, comunicação pessoal, 22 de outubro de 2017).

No entanto, o leque de indicações e apostas de ampliação da atuação da psicologia nos espaços de IST/HIV-Aids, não deve significar um menosprezo à dimensão da escuta psicológica subjetivada, 
como apontado pela fala de uma das profissionais, atenta às necessidades apresentadas pelos(as) usuários(as):

Mas às vezes [nome da entrevistadora], o paciente tá num estado de recolhimento tão grande, que é preciso que ele venha mais pra as consultas de psicologia pra que ele possa se sentir mais fortalecido psiquicamente até pra conviver com esses... com essas redes de apoio social, porque tem alguns que não querem nem... nem ter naquele momento... é... entrar em contato com o outro, né? (Gardênia, comunicação pessoal, 14 de outubro de 2017).

Portanto, não podemos olvidar que são as necessidades das pessoas que indicam quais recursos devem ser acionados para atendê-las. O imperativo da integralidade da atenção à saúde não deve impor rotinas e procedimentos em que cada dimensão do cuidado seja igualmente acionada para todos os casos (Campos, 2012). Assim, a ampliação da clínica psicológica nos espaços de atenção às IST/HIV-Aids e nos contextos de saúde pública não pressupõe o menosprezo das intervenções e atividades típicas do núcleo de saberes e fazeres da psicologia, mas a adaptação e inclusão de outros meios de intervenção para dar conta de toda a complexidade das demandas que chegam aos serviços e dos objetivos dos programas e políticas públicas de saúde. Para alguns autores, como Martins (2012), Scarcelli e Junqueira (2011), porém, essa articulação não ocorre sem algum conflito, pois o convite para a(o) psicóloga(o) atuar a partir da inclusão das dimensões sociais, políticas e culturais nem sempre encontra ressonância em uma formação marcada pela tradição da clínica clássica. O risco é que as diretrizes e princípios que organizam as políticas públicas sejam os únicos organizadores das práticas psicológicas nesses espaços (Martins, 2012). Dessa forma, a atuação nos contextos de saúde pública requer uma capacidade crítica das(os) profissionais, de forma a integrar saberes e fazeres a favor da produção de saúde, sem render-se à normatividade das políticas públicas de saúde.

Em suma, a compreensão do cuidado integral à saúde tem favorecido a atenção aos princípios e políticas do SUS, que têm sido incorporados aos atendimentos psicológicos dos(as) usuários(as) nos serviços pesquisados. Entretanto, essa não é uma realidade na rotina de todas(os) as(os) profissionais entrevistadas(os). As(os) psicólogas(os) de orientação psicanalítica ainda apostam em intervenções mais voltadas ao cuidado da dimensão subjetiva dos(as) usuários(as), na direção da construção da autonomia dos sujeitos em atendimento. A despeito disso, admitem a possibilidade de ampliação da atuação psicológica nos serviços de IST/HIV-Aids.

A clínica clássica não foi significada como um ideal de atuação, ainda que os atendimentos individuais em psicologia abranjam grande parte da rotina das(os) profissionais entrevistadas(os). Nesse cenário, o termo clínica ampliada foi utilizado pelas(os) psicólogas(os) para definir a clínica exercida no contexto da saúde pública/coletiva. Todavia, aspectos sobre o conceito de atuação "clínica clássica" permeiam as falas das(os) profissionais, mesmo que na tentativa de diferenciar-se dessa atuação quando inseridas(os) em serviços de saúde pública.

De uma forma geral, as(os) interlocutoras(es) dessa pesquisa reconheceram demandas não circunscritas à dimensão subjetiva dos(as) usuários(as). Apesar disso, não foram todas(os) que admitiram o espaço de escuta psicológica como o lugar para atender também a demandas relativas às dimensões sociais e biológicas da clientela atendida, na direção da construção de uma clínica social e culturalmente orientada, uma escuta mais cautelosa e menos asséptica (Lima, 2005) nos serviços de saúde pública.

\section{Considerações finais}

Uma produção significativa de estudos nas últimas décadas tecem críticas à inserção e atuação descontextualizada das(os) psicólogas(os) nos serviços de saúde pública. Essas críticas têm sido reproduzidas e tomadas como ponto de partida, consolidando verdades, além de serem reconhecidas como um mal decorrente da formação oferecida às(aos) estudantes de psicologia. Por sua vez, alguns estudos que tratam da atuação em serviços de IST/HIV-Aids têm apontado para construção de práticas mais comprometidas com os contextos de atuação, incentivando novos estudos que problematizem essas verdades tidas, muitas vezes, como absolutas.

Nessa direção, embasadas na perspectiva teórico-metodológica do construcionismo social, particularmente no campo da psicologia social e, ainda mais especialmente, na abordagem das práticas discursivas e produção de sentido, buscamos compreender como esses conhecimentos, construídos no tempo longo da psicologia como ciência e profissão em sua interface com a saúde pública/coletiva, são atualizados 
no cotidiano do trabalho (tempos vivido e curto), produzindo práticas discursivas e sentidos sobre o que ocorre nos serviços de saúde pública/coletiva e suas especificidades na atuação psicológica no âmbito da abordagem do IST/HIV-Aids. Ressaltamos que os repertórios linguísticos das(os) nossas(os) interlocutoras(es) apontaram para expressivas rupturas e ressignificações gestadas no cotidiano das práticas em saúde (tempo vivido e tempo curto), atentas às necessidades dos contextos de atuação, ainda que elementos da formação clássica da psicologia também sejam utilizados para caracterizar a atuação nesses espaços.

Realizando um esforço de caracterizar a atuação psicológica nos serviços de IST/HIV-Aids, utilizamos as categorias objeto, objetivo e meios de intervenção da clínica psicológica com o intuito de dialogar com os conceitos trazidos pela noção de clínica ampliada em saúde (Campos, 1996/1997, 2012). Dessa forma, concluímos que as(os) psicólogas(os) têm conseguido enxergar e reconhecer demandas de ordens biológica e social, que indicam aspectos objetivos da vivência dos(as) usuários(as) (menos afeitos ao ideário individualista), por meio da escuta exercida nesses espaços, embora nem todas(os) admitam que essas demandas devam ser cuidadas também pela(o) profissional de psicologia.

Destacamos que essa ampliação aponta para uma abertura das(os) profissionais para as atividades do campo da saúde. Porém, sinalizamos também que a simples ampliação das ações pode significar, em alguma medida, uma aderência acrítica às normativas da saúde pública, com desconsideração às peculiaridades da formação em psicologia. Não percebemos vantagens em seguirmos na direção da submissão da psicologia como campo de conhecimento e mesmo de práticas submetidas a qualquer normativa acrítica da saúde pública, que venham a ser protocolares, não considerem as singularidades do sofrimento e que se pautem excessivamente na racionalidade biomédica.

A ampliação da clínica psicológica no contexto da saúde pública/coletiva apresenta-se, portanto, como um processo em construção, mesmo dentro da trajetória de cada profissional. Isso porque um(a) único(a) profissional, em diferentes momentos, realiza ações e assume posturas que $\mathrm{a}(\mathrm{o})$ aproxima ou distancia da proposta da clínica ampliada em saúde. Não existiram dicotomias em que uma profissional assumiu apenas uma postura restrita e outra(o), somente uma postura ampliada da clínica. Apesar disso, alguns repertórios linguísticos apontaram para trajetórias profissionais mais sensíveis às demandas e propostas do contexto de atuação e à construção de atuações mais afeitas a essas necessidades. Dessa forma, a construção da clínica ampliada em psicologia se dá entre aproximações e recuos do que seria uma prática clínica mais contextualizada e comprometida com as características do campo de atuação.

Assim, reconhecendo que a realidade é socialmente construída e que a todo momento estamos forjando-a, em nossas relações sociais (Aragaki, Spink, \& Bernardes, 2012), não tomamos os conhecimentos e práticas atualmente produzidos pela psicologia como inevitáveis e definitivos. Dessa forma, esperamos que este estudo possa contribuir para ampliar a discussão sobre a inserção e atuação de psicólogas(os) em serviços públicos de saúde, de forma geral e especificamente no campo das IST/HIV-Aids, fomentando a reflexão em torno dos saberes e fazeres construídos e produzindo novos discursos e práticas discursivas mais engajadas com as necessidades dos diversos contextos de atuação.

\section{Referências}

Aragaki, S. S., Spink, M. J., \& Bernardes, J. S. (2012). La Psicología de la Salud en Brasil: Transformaciones de las prácticas psicológicas en el contexto de las políticas públicas en el área de la salud. Pensamiento Psicológico, 10(2), 65-82. http://www.scielo.org.co/scielo.php?script=sci_arttext\&pid=S1657-89612012000200007\&lng=en\&tlng=es

Campos, G. W. S. (1996/1997). Uma clínica do sujeito: Por uma clínica reformulada e ampliada [Artigo não publicado]. http://www.pucsp.br/prosaude/downloads/bibliografia/CLINICAampliada.pdf

Campos, G. W. S. (2000). Saúde pública e saúde coletiva: campo e núcleo de saberes e práticas. Ciência \& Saúde Coletiva, 5(2), 219-230. http://doi.org/10.1590/S1413-81232000000200002

Campos, G. W. S. (2012). Clínica e saúde coletiva compartilhadas: Teoria paideia e reformulação ampliada do trabalho em saúde. In G. W. S. Campos, M. C. S. Minayo, M. Akerman, M. Drumond Júnior \& Y. M. Carvalho (Orgs.), Tratado de saúde coletiva (2a ed. rev. e aum, pp. 53-92). Hucitec. 
Gomes, E. S. S., \& Lima, M. (2022). Clínica psicológica ampliada em IST/HIV-Aids.

Campos, G. W. S., \& Amaral, M. A. (2007). A clínica ampliada e compartilhada, a gestão democrática e redes de atenção como referenciais teórico-operacionais para a reforma do hospital. Ciência \& Saúde Coletiva, 12(4), 849-859. http://doi.org/10.1590/S1413-81232007000400007

Conselho Federal de Psicologia. (2008). Referências técnicas para a atuação do(a) psicólogo(a) nos Programas de DST e aids. http://crepop.pol.org.br/wp-content/uploads/2010/11/DST_AIDS.pdf

Conselho Nacional de Saúde. (2016). Resolução n. 510, de 7 de abril de 2016. Diário Oficial da União.

Conselho Nacional de Saúde. (2012). Resolução n. 466, de 12 de dezembro de 2012. Diário Oficial da União.

Costa, L. F., \& Brandão, S. N. (2005). Abordagem clínica no contexto comunitário: uma perspectiva integradora. Psicologia \& Sociedade, 17(2), 33-41. http://doi.org/10.1590/S0102-71822005000200006

Cunha, G. T. (2005). A construção da clínica ampliada na atenção básica. Hucitec.

Dettmann, A. P. S., Aragão, E. M. A., \& Margotto, L. R. (2016). Uma perspectiva da Clínica Ampliada: as práticas da psicologia na assistência social. Fractal:Revista de Psicologia, 28(3), 362-369. http:// doi.org/10.1590/1984-0292/1232

Dimenstein, M. (2000). A cultura profissional do psicólogo e o ideário individualista: Implicações para a prática no campo da assistência à saúde. Estudos de psicologia, 5(1), 95-121. http://doi.org/10.1590/ S1413-294X2000000100006

Dimenstein, M. (2001). O psicólogo e o compromisso social no contexto da saúde coletiva. Psicologia em Estudo, 6(2), 57-63. http://www.scielo.br/pdf/pe/v6n2/v6n2a08.pdf

Dimenstein, M., \& Macedo, J. P. (2012). Formação em Psicologia: Requisitos para Atuação na Atenção Primária e Psicossocial.Psicologia:CiênciaeProfissão,32(n.esp.),232-245.http://doi.org/10.1590/S1414-98932012000500017

Ferreira Neto, J. L. (2008). Práticas transversalizadas da clínica em saúde mental. Psicologia: Reflexão e Crítica, 21(1), 110-118. http://doi.org/10.1590/S0102-79722008000100014

Ferreira Neto, J. L. (2010). A atuação do psicólogo no SUS: Análise de alguns impasses. Psicologia: Ciência e Profissão, 30(2), 390-403. http://pepsic.bvsalud.org/scielo.php?script=sci_arttext\&pid=S1414-98932010000200013

Figueiredo, M. A. C. (2004). Suporte psicossocial ao cuidado doméstico de pessoas com hiv/aids. Um estudo com base na tríade paciente/profissional/familiar. Revista da SPAGESP, 5(5), 62-66. http://pepsic.bvsalud.org/scielo. php?script=sci_arttext\&pid=S1677-29702004000100011\&lng=pt\&tlng=pt

Galindo, W. C. M., Francisco, A. L., \& Rios, L. F. (2013). A instrução e a relação como modos de aconselhamento em HIV/Aids. Temas em Psicologia, 21(3), 989-1004. http://doi.org/10.9788/TP2013.3-EE12PT

Garbin, C. A. S., Garbin, A. J. I., Moimaz, S. A. S., \& Carmo, M. P. (2009). Bioética e HIV/Aids: Discriminação no atendimento aos portadores. Revista Bioética, 17(3), 511- 522. http://revistabioetica.cfm.org.br/index.php/ revista_bioetica/article/viewFile/514/515

Gomes, E. S. S. (2018). Práticas discursivas sobre atuação psicológica em Hiv-aids: sentidos produzidos no cotidiano dos serviços públicos de saúde em uma cidade da Bahia [Dissertação de mestrado, Instituto de Psicologia da Universidade Federal da Bahia].

Jesus, G. J., Oliveira, L. B., Caliari, J. S., Queiroz, A. A. F. L., Gir, E., \& Reis, R. K. (2017). Dificuldades do viver com HIV/Aids: Entraves na qualidade de vida. Acta Paulista de Enfermagem, 30(3), 301-307. http://doi.org/ 10.1590/1982-0194201700046

Lima, M. (2005). Atuação Psicológica em Serviços de Saúde de Salvador: Do ponto de vista dos psicólogos [Tese de doutorado não-publicada]. Instituto de Saúde Coletiva da Universidade Federal da Bahia.

Lo Bianco, A. C., Bastos, A. V. B., Nunes, M. L. T., \& Silva, R. C. (1994). Concepções e atividades emergentes na psicologia clínica: implicações para a formação. In R. Achcar (Org.), Psicólogo brasileiro: Práticas emergentes e desafios para a formação (4a ed., pp. 17-100). Casa do psicólogo.

Martins, R. B. (2012). O programa de DST/Aids e a formação em psicologia: Determinações e contradições para o trabalho do psicólogo [Tese de doutorado, Instituto de Psicologia da Universidade de São Paulo].

Massignani, L. M., Rabuske, M. M., Backes, M. S., \& Crepaldi, M. A. (2014). Comunicação de diagnóstico de soropositividade HIV e aids por profissionais de saúde. Psicologia Argumento, 32(79), 65-75. http://10.7213/psicol..argum.32.s02.AO06

Meira, I. F., Gama, I. B., Almeida, M. S., Souza, S. S., Oliveira, T. N. M. G., \& Albuquerque, R. N. (2017). Reflexões psicossociais acerca do HIV e AIDS e contribuições da Psicologia. Revista Hum@Nae, 11(1). http://humanae.esuda. com.br/index.php/humanae/article/view/464/176 
Melo, E. S., Rozendo, C. A., Argolo, J. G. M., Queiroz, A. A. F. L. N., Gir, E., \& Reis, R. K. (2017). Mecanismos de enfrentamento utilizados por mulheres vivendo com HIV/aids. Revista Cubana de Enfermería, 33(3). http://www.revenfermeria.sld.cu/index.php/enf/article/view/1308/289

Monteiro, J. F. A. (2006). O processo de trabalho em HIVIAids: A visão dos profissionais [Dissertação de mestrado, Departamento de Psicologia e Educação da Universidade de São Paulo].

Monteiro, J. F. A., \& Figueiredo, M. A. C. (2009). Vivência profissional: Subsídios à atuação em HIV/Aids. Paidéia, 19(42), 67-76. http://doi.org/10.1590/S0103-863X2009000100009

Moreira, J. O., Romagnoli, R. C., \& Neves, E. O. (2007). O surgimento da clínica psicológica: Da prática curativa aos dispositivos de promoção da saúde. Psicologia: Ciência e Profissão, 27(4), 608-621. https://doi.org/10.1590/ S1414-98932007000400004

Perucchi, J., Rodrigues, F. D., Jardim, L. N., \& Calais, L. B. (2011). Psicologia e políticas públicas em HIV/Aids: algumas reflexões. Psicologia \& Sociedade, 23(n.spe.), 72-80. http://doi.org/10.1590/S0102-71822011000400010

Pires,A.C.T.,\&Braga,T.M.S. (2009).Opsicólogonasaúdepública:Formaçãoeinserçãoprofissional. TemasemPsicologia, 17(1), 151-162. http://pepsic.bvsalud.org/scielo.php?script=sci_arttext\&pid=S1413-389X2009000100013

Portela, M. A. (2008). A crise da psicologia clínica no mundo contemporâneo. Estudos de Psicologia, 25(1), 131-140. http://doi.org/10.1590/S0103-166X2008000100013

Rasera, E. F., \& Issa, C. L. G. (2007). A atuação do psicólogo em ONG/Aids. Psicologia: Ciência e Profissão, 27(3), 566-575. https://doi.org/10.1590/S1414-98932007000300015

Scarcelli, I. R., \& Junqueira, V. (2011). O SUS como desafio para a formação em Psicologia. Psicologia: Ciência e Profissão, 31(2), 340-357. http://doi.org/10.1590/S1414-98932011000200011

Schneider, D. R., Oltramari, L., Budde, C., Silveira, A. L., \& Silveira, S. (2016). A clínica na comunidade: Uma experiência de intervenção intersetorial para adolescentes em situação de vulnerabilidade psicossocial. Cadernos Brasileiros de Saúde Mental, 8(18), 68-80. https://periodicos.ufsc.br/index.php/cbsm/article/view/69285/41590

Silva, L. M. S. (2017). O HIV às vezes me assombra: Narrativas online de mulheres jovens vivendo com HIV/aids acerca das suas relações afetivo-sexuais [Dissertação de mestrado, Instituto de Saúde Coletiva da Universidade Federal da Bahia].

Silva, R. S. D., \& Albuquerque, V. S. (2007). Sexualidade no cotidiano de portadores do vírus HIV. Jornal Brasileiro de Aids, 8(2) 66-77. https://pesquisa.bvsalud.org/brasil/resource/pt/lil-458457

Spink, M. J. P. (2010). Linguagem e produção de sentidos no cotidiano. Centro Edelstein de Pesquisas Sociais.

Spink, M. J. P., \& Matta, G. C. (2007). A prática profissional Psi na saúde pública: Configurações históricas e desafios contemporâneos. In M. J. P. Spink (Org.), A psicologia em diálogo com o SUS: Prática profissional e produção acadêmica (pp. 25-51). Casa do Psicólogo.

Spink, M. J. P., \& Menegon, V. M. (2013). A pesquisa como prática discursiva: Superando os horrores metodológicos. In M. J. Spink (Org.), Práticas discursivas e produção de sentidos no cotidiano (pp. 21-49). Centro edlstein de pesquisas sociais.

Sundfeld, A. C. (2010). Clínica ampliada na atenção básica e processos de subjetivação: Relato de uma experiência. Physis: Revista de Saúde Coletiva, 20(4), 1079-1097. http://doi.org/10.1590/S0103-73312010000400002

Tykanori, R. (2001). Contratualidade e reabilitação psicossocial. In A. Pitta (Org.), Reabilitação psicossocial no Brasil (2a ed., pp. 55-59). Hucitec.

Vázquez-Sixto, F. (1996). El análisis de contenido temático. Objetivos y medios en la investigación psicosocial [Documento de trabajo]. Universitat Autònoma de Barcelona.

Yamamoto, O. H., \& Oliveira, I. F. (2010). Política Social e Psicologia: Uma trajetória de 25 anos. Psicologia: Teoria e Pesquisa, 26(n. spe.), 9-24. http://doi.org/10.1590/S0102-37722010000500002 


\section{Emilly Sales Sala Gomes}

Psicóloga, Mestra e Doutoranda no Programa de Pós-Graduação em Psicologia da Universidade Federal da Bahia (UFBA), Salvador - BA, Brasil. Especialista em Saúde da Família pelo Programa de Residência Multiprofissional em Saúde da Família da Universidade Federal de Pernambuco (UFPE), Recife - PE, Brasil.

E-mail: emillysala@gmail.com

(1) https://orcid.org/0000-0003-4765-4338

\section{Mônica Lima}

Professora Associada IV do Instituto de Psicologia da Universidade Federal da Bahia (UFBA), Salvador - BA, Brasil. Professora permanente do Programa de Pós-Graduação em Psicologia da UFBA. Graduada em Psicologia pela UFBA. Mestra e Doutora em Saúde Pública/Coletiva pelo Instituto de Saúde Coletiva da UFBA. Pós-doutorado em Psicologia Social pela Universidad Antónoma de Barcelona (UAB), Barcelona, Espanha.

E-mail: molije@hotmail.com

(1) https://orcid.org/0000-0002-6666-8463

Financiamento:

O presente trabalho foi realizado com apoio da Coordenação de Aperfeiçoamento de Pessoal de Nível Superior - Brasil (Capes) - Código de Financiamento 001.

Endereço para envio de correspondência:

Rua Hamilton Carvalho Lima, 51, Ed. Colômbia, ap. 101, Bairro Trobogy. CEP: 41745-026. Salvador - BA. Brasil.

Recebido 16/01/2020

Aceito 09/08/2021

Received $01 / 16 / 2020$

Approved 08/09/2021

Recibido 16/01/2020

Aceptado 09/08/2021

Como citar: Gomes, E. S. S., \& Lima, M. (2022). Clínica psicológica ampliada em IST/HIV-Aids: Sentidos produzidos por psicólogas no SUS. Psicologia: Ciência e Profissão, 42, 1-15. https://doi.org/10.1590/1982-3703003233089

How to cite: Gomes, E. S. S., \& Lima, M. (2022). Amplified clinic in STI/HIV-AIDS: Meanings produced by psychologists in Brazilian Health Public System (SUS). Psicologia: Ciência e Profissão, 42, 1-15. https://doi.org/ 10.1590/1982-3703003233089

Cómo citar: Gomes, E. S. S., \& Lima, M. (2022). Clínica psicológica ampliada en ITS/VIH-sida: Sentidos producidos por psicólogas en el Sistema Único de Salud (SUS). Psicologia: Ciência e Profissão, 42, 1-15. https://doi.org/ 10.1590/1982-3703003233089 